\title{
Q
}

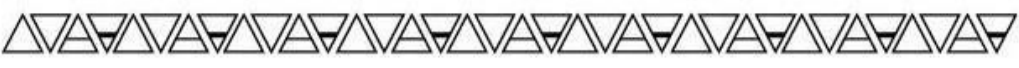

DOI 10.31418/2177-2770.2019.v11.c2.p130-154 | ISSN 2177-2770

Licenciado sob uma Licença Creative Commons

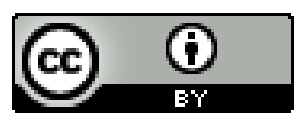

\section{MEMÓRIA, INFORMAÇÃO E ENCANTO: A ESFERA DE SABERES ENTRE OS MESTRES DA TRADIÇÃO ORAL}

\section{Edison Luís dos Santos ${ }^{1}$}

Resumo: Apresenta estudo parcial de natureza exploratória do processo de produção partilhada de saberes entre mestres e aprendizes da cultura de tradição oral. A trama conceitual contempla o jogo de forças sociais, disputa de formas, possibilidades, arranjos e ordenamento do conhecimento, por meio de abordagem epistêmica que perpassa pelo reconhecimento ontológico das bibliotecas vivas no processo de "produção partilhada de saberes" como solução de demandas por apropriação de memórias e circulação social de informações. Neste diálogo, experimentamos uma relação com o saber, voluntária e coletiva, da "ciência como artesanato", cuja materialização se deu no fazer prático (savoir-faire) por meio do qual os sujeitos do saber aprenderam a conhecer e a fazer colaborativamente.

Palavras-chave: Cultura, Memória, Informação, Tradição oral, Educação.

\section{MEMORY, INFORMATION AND ENCHANTMENT: THE SPHERE OF KNOWLEDGE AMONG THE MASTERS OF ORAL TRADITION}

\begin{abstract}
Presents a partial exploratory study of the process of shared production of knowledge between teachers and learners of oral tradition culture. The conceptual framework contemplates the game of social forces, a dispute of forms, possibilities, arrangements and ordering of knowledge, through an epistemic approach that passes through the ontological recognition of living libraries in the process of "shared production of knowledge" as a solution of demands for appropriation of memories and social circulation of information. In this dialogue, we have experienced a relationship with the voluntary and collective knowledge of "science as a handicrafts", whose materialization took place in the savoir-faire through which the subjects of knowledge learned to know and to do collaboratively.
\end{abstract}

Keywords: Culture, Memory, Information, Oral tradition, Education.

\section{MEMOIRE, INFORMATION ET CHARME: LA SPHERE DE LA CONNAISSANCE PARMI LES MAITRES DE LA TRADITION ORALE}

Résumé: L'article présente une étude exploratoire partielle du processus de production partagée de connaissances entre enseignants et apprenants de la culture de la tradition orale. Le cadre conceptuel envisage le jeu des forces sociales, un conflit de formes, de possibilités, d'arrangements et de classement des connaissances, à travers une approche épistémique qui passe par la reconnaissance ontologique de bibliothèques vivantes dans le processus de «production partagée de connaissances» comme solution de demandes d'appropriation des mémoires et de la circulation sociale de l'information. Dans ce dialogue, nous avons expérimenté une relation avec

\footnotetext{
${ }^{1}$ Pesquisador da USP, graduado em Linguística - FFLCH-USP e Biblioteconomia - ECA-USP; Mestre e Doutor em Ciência da Informação, pela Escola de Comunicações e Artes, da Universidade de São Paulo. E-mail: edisonlz@usp.br
} 
la connaissance volontaire et collective de «la science en tant qu'artisan», dont la matérialisation s'est matérialisée par le savoir-faire à travers lequel les sujets de la connaissance ont appris à connaitre et à travailler en collaboration.

Mots-clés: Culture, Mémoire, Information, Tradition orale, Education.

\section{MEMORIA, INFORMACIÓN Y ENCANTO: LA ESFERA DE SABERES ENTRE LOS MAESTROS DE LA TRADICIÓN ORAL}

Resumen: El artículo presenta un estudio parcial de naturaleza exploratoria del proceso de producción compartida de saberes entre maestros y aprendices de la cultura de tradición oral. La trama conceptual contempla el juego de fuerzas sociales, disputa de formas, posibilidades, arreglos y ordenación del conocimiento, por medio de abordaje epistémico que atraviesa el reconocimiento ontológico de las bibliotecas vivas en el proceso de "producción compartida de saberes" como solución de demandas por apropiación de memorias y circulación social de informaciones. En este diálogo, experimentamos una relación con el saber, voluntaria y colectiva, de la "ciencia como artesanía", cuya materialización se dio en el hacer práctico (savoir-faire) por medio del cual los sujetos del saber aprendieron a conocer ya hacer colaborativamente.

Palabras clave: Cultura, Memoria, Información, Tradición oral, Educación

\section{INTRODUÇÃO: CONHECER O QUE É CONHECER NAS FRONTEIRAS DO "SABER"}

O físico teórico Mario Schenberg costumava dizer aos seus discípulos, "Tudo o que é novo aparece aos olhos antigos como coisa errada. É sempre nessa violação do que é considerado certo que nasce o novo e há criação". O professor Schenberg imaginava poder demonstrar que não há incompatibilidade entre a fantasia e a razão, contrariando os colegas pesquisadores que ainda hoje defendem verticalmente que a "arte, criatividade e curiosidade científica estão relacionadas com a divulgação e vulgarização da ciência". ${ }^{2}$ $\mathrm{O}$ ato de comunicar resultados de pesquisa científica equivaleria, portanto, a transformar em linguagem pública o discurso cifrado ou especializado do "produtor de conhecimento", ou cientista "esclarecido".

Com o advento dos novos modos de viver, a invasão de dispositivos diferenciados de produção, guarda e transmissão de informações e conhecimentos produziu mudanças contundentes que afetaram diferentes níveis da esfera global. $\mathrm{O}$ dilúvio informacional gerado pelo crescente desenvolvimento científico e tecnológico

\footnotetext{
${ }^{2}$ A propósito, os termos vulgarization (franc.) e divulgação (port.) contêm o radical do lexema "vulgo" que significa o povo, a plebe (vulgar, popular, do senso comum). Dessa maneira, divulgação e vulgarização da ciência "carregam em si a ideia de desprestígio, de secundariedade, com relação ao saber científico, que traria, por oposição, a ideia de primariedade, de prestígio, aplicada à ciência que, por sua vez, detém os preconceitos de sabedoria e conhecimento...". (Coracini, 1992, p. 81-86).
} 
condenou "saberes" da tradição oral ao esquecimento, relegando-os à esfera do folclore, do popular, nostálgico...

Curiosamente, nessa "esfera das espumas" em que vivemos, cuja natureza sociotécnica é permeada por estruturas líquidas, arquiteturas movediças e novas formas de comportamento comunicativo, paralela e simultaneamente linguagens híbridas e novas topologias criam, potencialmente, lugares de memória e produzem conhecimentos por meio de redes sociotécnicas. A esfera das espumas caracteriza-se pela volatilidade... Tudo se move, pessoas, coisas, valores, ideias.

Eis o caráter paradoxal de uma nova condição de vida... Uma nova concepção de mundo passou a deixar deslocado, fora de tempo, tudo aquilo que não representa o "sempre novo e atual". Nesse contexto, a memória tornou-se matéria suplementar, dispensável à formação da infância e da juventude; quando muito, foi tomada sob o aspecto romântico e nostálgico, de culto ao passado, porém, desconsiderada em seu significativo papel de guarda e transmissão de saberes que deve retornar sob uma nova forma (experiência e sabedoria de vida) vital ao desenvolvimento das gerações:

A experiência da vida insere-se na relação do homem com o mundo, consigo próprio e com os outros. (...) É nas manifestações simbólicas da cultura que o homem preenche o abismo que o separa das coisas, de si próprio e dos outros, acedendo assim à consciência reflexiva e à experiência da vida em comum. Pela linguagem, a experiência simbólica por excelência, o homem prossegue o ilimitado trabalho de preenchimento deste abismo e a elaboração de um sentido para o enigma da vida. (Rodrigues, 1994, p. 106)

A experiência está ligada a processos de acumulação de um saber interessado em valores construídos durante a existência, não se tratando de um saber especializado. Ao contrário, o conceito de "experiência" refere-se ao saber elaborado pouco a pouco feito e refeito -, ao longo da vida, pressupondo um determinado contexto que também permita sua transmissão. Na experiência dos mestres da tradição oral encontram-se sintetizadas as sucessivas incorporações de saber elaboradas e reelaboradas por gerações.

Ao lado da história escrita, tipicamente marcada por registros de datas, descrição de períodos, há uma série de correntes do passado que parecem ilhas efêmeras de uma cultura que representam estilos ou resquícios de outras épocas, modos de pensar e maneiras de sentir e se relacionar com o mundo de uma determinada cultura, que não podem ser compreendidos senão em sua expressão típica e vinculada à cultura. 
Mesmo que uma cultura esteja em franco processo de mudança, os vínculos com o passado ainda podem ser conservados por meio do contato com os mais velhos, especialmente, nas sociedades que mantêm e valorizam a cultura oral. Existem sociedades orais nas quais o ancião é o maior bem social, possui um lugar privilegiado e a sua voz é honrada, conforme descreve uma lenda registrada por Ecléa Bosi:

Uma lenda balinesa fala de um longínquo lugar, nas montanhas, onde outrora se sacrificavam os velhos. Com o tempo não restou nenhum avô que contasse as tradições para os netos. A lembrança das tradições se perdeu. Um dia quiseram construir um salão de paredes de tronco para a sede do Conselho. Diante dos troncos abatidos e já desgalhados os construtores viam-se perplexos. Quem diria onde estava a base para ser enterrada e o alto que serviria de apoio para o teto? Nenhum deles poderia responder: há muitos anos não se levantavam construções de grande porte, e eles tinham perdido a experiência. Um velho que havia sido escondido pelo neto, aparece e ensina a comunidade a distinguir a base e o cimo dos troncos. Nunca mais um velho foi sacrificado. (Bosi, 1994, p. 76-77)

Sob este aspecto, a fala do narrador, isto é, a comunicação das bibliotecas vivas atua como instrumento capaz de dar forma às realidades interiores, tanto quanto conectar outras realidades a serem alcançadas na relação entre os interlocutores com a experiência (jovens, crianças, estudantes, pesquisadores etc.). Pode ser compreendida como forma de ação sobre a realidade sociocultural da comunidade, tanto quanto de atuação política: de intervenção sobre o mundo imediato. No complexo quadro de "silenciamento e apagamento do vivido" em comunidades de tradição oral, dispositivos de informação podem atuar em direção distinta, refazendo percursos ao rever sua atuação, buscando incluir, por meio de produção partilhada, repertórios essenciais ao processo de apropriação e significação do mundo pelos sujeitos (desconsiderados em suas práticas tradicionais).

\section{EPISTEMOLOGIA DO SENSO COMUM: A "ESFERA PRIMORDIAL} DO VIVIDO"

Em decorrência do projeto iluminista, à luz da "esfera da razão", as questões relacionadas à memória e à imaginação, por dedução, passaram a fazer parte do reino das sombras, ilusão e superstição, tendo sido preteridas por seu valor residual, contingente. Em outras palavras, para a "clareira da ciência" do século XVII o conhecimento comum era o conhecimento das crenças tradicionais (considerado superficial, ilusório e falso), de 
modo que tudo o que carecia de objetividade, tudo que não tinha método, enfim, tudo isso pertencia à esfera da vida cotidiana, da superficialidade dos saberes ordinários que brotam do "common sense". 3

Hoje em dia, contudo, a esfera do cotidiano adquiriu novos matizes com a importância a que foram alçados os saberes locais no contexto da aldeia global. Embora tenha se tornado foco de maior atenção, a esfera do senso comum continua sendo um fenômeno desdenhado; ou seja, apesar de presumido, não costuma ser analisado, é pouco explorado. Clifford Geertz admite a dificuldade de formular as especificidades do senso comum, pois não existe um vocabulário já elaborado com o qual expressá-lo. De acordo com as atribuições do autor, suas principais propriedades (um tanto ou quanto incomuns) são as seguintes: naturalidade, praticabilidade, leveza, não-metodicidade e acessibilidade. (Geertz, 2014, p. 88-97).

Em termos bem práticos, Geertz faz a seguinte comparação: “a religião baseia seus argumentos na revelação, a ciência na metodologia, a ideologia na paixão moral; os argumentos do senso comum, porém, não se baseiam em coisa alguma, a não ser na vida como um todo. O mundo é sua autoridade”. (Geertz, 2014, p. 79)

Já não podemos negligenciar o caráter prático do "conhecimento comum", que é um sistema constituído pelas tradições, ocupações, técnicas, interesses, pensamento cíclico. De acordo com Michel Maffesoli, “o conhecimento ordinário chama à baila a surpresa e o abalo que, há muito, instituem e constituem os fundamentos de toda obra de pensamento. Ele prepara as armas, polindo-as para sutis partidas de caça que, aqui e agora, dizem respeito ao que se vem procurando: a vida em seu eterno recomeço, a vida em sua dimensão eterna”. (Mafessoli, 2010, p. 16, grifo do autor)

No contexto brasileiro, as religiões e as formas de expressão artística popular, bem como preceitos da medicina de tradição oral, sistemas de feitiçaria, técnicas de cuidado com o corpo, o folclore, entre outros fenômenos semelhantes, eram (e ainda são) pensados como expressões particulares de uma mente "primitiva", "rude", "ingênua", "ignorante"; ou seja, sinais de um suposto "atraso cultural", carentes de uma percepção objetiva e racional do mundo.

\footnotetext{
${ }^{3} \mathrm{O}$ pensador napolitano Giambattista Vico (1668-1744) rejeitava o "apelo à autoconsciência" contido no Cogito, bem como o princípio que faz das ideias claras e distintas o critério universal da verdade. Para ele, o homem só conhece verdadeiramente aquilo que faz ou cria; contrapõe à razão cartesiana o Engenho faculdade de descobrir o verossímil e o novo: "Onde Descartes dera ênfase à necessidade de 'ideias claras e distintas', Vico afirmava que o conhecimento aparentemente claro e distinto é um vício, não uma virtude do entendimento humano". (BURKE, 1997, p. 34)
} 
$\mathrm{Na}$ contramão desse discurso racionalista que ataca a "discursividade primordial do vivido", Mário de Andrade e Luís da Câmara Cascudo desenvolveram pesquisas férteis e trabalhos etnográficos de observação e registro das diversas formas de vida sociocultural, usualmente classificadas como "folclóricas" ou "populares" (alimentação, redes de dormir, jangada e jangadeiros, literatura oral, gestos, expressões cotidianas, superstições, práticas e crenças de feitiçaria, cachaça, vaqueiros e cantadores, festas populares, festas religiosas). Sobre a sabedoria prática e a imaginação do "senso comum", Luís da Câmara Cascudo destaca o significado das relações entre memória e tradição, em seu livro Tradição, ciência do povo, uma reunião de investigações sobre a ciência (saberes e fazeres) da gente viva; segundo ele, nesta obra quem fala é "o brasileiro dos sertões, cidades-velhas, e praias, sem constrangimento e disfarce":

A memória é a imaginação do povo, mantida comunicável pela tradição, movimentando as culturas, convergidas para o uso, através do tempo. Essas culturas constituem quase a civilização nos grupos humanos. Mas existe um patrimônio de observações que se tornam normas. Normas fixadas no costume, interpretando a mentalidade popular. [...] Não lhe sentimos a poderosa e onímoda influência como não percebemos a pressão atmosférica em função normal. Nem provocam atenção porque vivem no habitualismo quotidiano. (Câmara Cascudo, 1971, p. 9)

$\mathrm{Na}$ introdução, o autor potiguar também faz questão de fazer referência ao método usado: "Não bibliotecas, mas convivência". De antemão, adverte o leitor que a tradição, entendida como "ciência do povo", é caracterizada pela permanência, por ser quase intangível pelo tempo e por remeter, através de cada particular, ao Universal. As falas dos poetas e repentistas populares são comumente marcadas por observações sutis; são impressões e expressões espontâneas que "fixam imagens sem idade, resultados de longos e obscuros processos de raciocínio, critérios-soluções, herdadas, indeformáveis, e reproduzidas íntegras [...] Gestos, frases, que perderam explicações e resistem na velocidade anterior, quase sem os atritos do tempo". (Câmara Cascudo, 1971, p. 10)

\section{MESTRES DO SABER: O DEVIR DAS BIBLIOTECAS VIVAS}

Nas tribos primitivas, os velhos são os guardiões das tradições, não só porque eles as receberam mais cedo que os outros mas também porque só eles dispõem do lazer necessário para fixar seus pormenores ao longo de conversações com os outros velhos, $e$ para ensiná-los aos jovens a partir da iniciação. (Halbwachs, 
Os velhos mestres e griôs são personagens importantes que remetem à tradição oral da África negra, especialmente nas sociedades do noroeste africano, em que a oralidade (e não a palavra escrita) é o principal meio de manutenção das culturas. Em vez do registro em livros e arquivos, é a circulação do conhecimento que garante que as culturas permaneçam vivas. De acordo com Amadou Hampâté Bâ, estudioso do tema,

A tradição oral é a grande escola da vida, e dela recupera e relaciona todos os aspectos. Pode parecer caótica àqueles que não lhe descortinam o segredo e desconcertar a mentalidade cartesiana acostumada a separar tudo em categorias bem definidas. Dentro da tradição oral, na verdade, o espiritual e o material não estão dissociados. Ao passar do esotérico para o exotérico, a tradição oral consegue colocar-se ao alcance dos homens, falar-lhes de acordo com o entendimento humano, revelar-se de acordo com as aptidões humanas. Ela é ao mesmo tempo religião, conhecimento, ciência natural, iniciação à arte, história, divertimento e recreação, uma vez que todo pormenor sempre nos permite remontar à Unidade primordial. (Bâ, 2010, p. 169)

A palavra griô tem sua origem em bamanan (língua do noroeste da África, antigo império do Mali) e o seu significado é: "o sangue que circula". Conforme explica Amadou Hampâté Bâ, os griôs são como trovadores ou menestréis, considerados agentes que dão continuidade à cadeia da transmissão oral, fazendo circular os saberes tradicionais. Existem várias categorias de mestres griôs. Eles podem ser músicos, adivinhos, contadores de história; “embaixadores” que atuam na mediação de conflitos entre as famílias nobres; e poetas, historiadores ou genealogistas que percorrem os países para descobrir e contar as origens dos troncos familiares. Nessa categoria, também podemos incluir um rol de mestres capoeiristas, antigos e atuais, como corresponsáveis pelas lutas e conquistas de reconhecimento da cultura negra no Brasil.

$\mathrm{Na}$ verdade, o termo Griô é universalizante, porque é um abrasileiramento do termo Griot, que por sua vez define um arcabouço imenso do universo da tradição oral africana. É uma corruptela da palavra "Creole”, ou seja, Crioulo, a língua geral dos negros na diáspora africana; uma recriação do termo "gritadores", reinventado pelos portugueses quando viam Griôs gritando em praça pública; também foi utilizado pelos estudantes afrodescendentes que estudavam na língua francesa para sintetizar milhares de definições que abarca. O termo griô tem origem nos músicos, genealogistas, poetas e comunicadores sociais, mediadores da transmissão oral, bibliotecas vivas de todas as histórias, os saberes e fazeres da tradição, sábios da tradição oral que representam nações, famílias e grupos 
de um universo cultural fundado na oralidade, onde o livro não tem papel social prioritário, e guardam a história e as ciências das comunidades, das regiões e do país. ${ }^{4}$

Em "A tradição viva", capítulo de especial interesse para a compreensão da tradição oral, justamente porque produzido por um insider, "de dentro" da tradição, Hampaté Bâ explica que, nas sociedades tradicionais africanas, existe forte ligação entre o homem e a palavra. O homem é a palavra que profere. A coesão social repousa no valor e no respeito pela palavra. A palavra falada possui valor moral e caráter sagrado, devido à sua origem divina e às forças ocultas nela depositadas.

A fala materializa as vibrações das forças vitais. No universo, tudo fala! A fala pode ser vista, ouvida, cheirada, saboreada, tocada. A tradição oral, que se constrói sobre a concepção da palavra como sacralidade, não se limita ao corpus de histórias e lendas ou de relatos mitológicos e históricos. São histórias, mitos e lendas que se tornam conhecimento vivo e de enorme eficácia pedagógica na vida das comunidades, abrangendo a totalidade de sua existência:

$\mathrm{Na}$ tradição africana, a fala, que tira do sagrado o seu poder criador e operativo, encontra-se em relação direta com a conservação ou com a ruptura da harmonia no homem e no mundo que o cerca. [...] Nas sociedades orais, não apenas a função da memória é mais desenvolvida, mas também a ligação entre o homem e a Palavra é mais forte. Lá onde não existe a escrita, o homem está ligado à palavra que profere. Está comprometido por ela. Ele é a palavra, e a palavra encerra um testemunho daquilo que ele é. A própria coesão da sociedade repousa no valor e no respeito pela palavra. (Bâ, 2010, p. 168)

A conversa evocativa de um "ancião" ou "mestre da tradição oral" caracterizase quase sempre por uma experiência profunda: "repassada de nostalgia, revolta, resignação pelo desfiguramento das paisagens caras, pela desaparição de entes amados, é semelhante a uma obra de arte. Para quem sabe ouvi-la, é desalienadora, pois contrasta a riqueza e a potencialidade do homem criador de cultura com a mísera figura do consumidor atual" (Bosi, 1994, p. 82). O universo social e simbólico das culturas de tradição oral possui uma riqueza e uma diversidade artístico-cultural que ainda não conhecemos ou simplesmente ignoramos. No entanto, tal legado poderia ser mais bem

\footnotetext{
${ }^{4}$ Em África, existem termos distintos em cada grupo étnico: Dioma, Dieli, Funa, Rafuma, Baba, Mabadi. Os povos originários do Brasil também reconhecem no termo Griô a definição de um lugar social e político na comunidade para transmissão oral dos saberes e fazeres, exemplo dos Kaingang do Sul, dos Tupinambá das Aldeias Tukun e Serra Negra (BA) e os Pankararu de Pernambuco, os Macuxi em Roraima, e tantos outros que participam da Rede Ação Griô Nacional, incluindo Morubixabas, Kanhgág Kanhró etc. Vale dizer que o termo "Griô" contempla todos. In: http://graosdeluzegrio.org.br/acao-grio-nacional/o-que-egrio/.
} 
compreendido por meio da memória dos mais velhos; quiçá, inclusive, poderia até humanizar mais o nosso presente.

\section{A LUTA PELA MEMÓRIA E A REINVENÇÃO DO COTIDIANO}

A luta pela memória, que se trava ao longo da história sociocultural da humanidade, faz parte do jogo de forças sociais em disputa por formas e possibilidades de inserção de "marcas" na sociedade. Em outros termos, cada indivíduo, cada grupo, comunidade, segmento, quer tornar público seus modos de ver e compreender o mundo expressar-se - buscando escapar e contingenciar o peso da existência, da ingrata presença da morte que ameaça todos os seres...

Os reflexos da "crise da memória" geraram rupturas entre as vivências individuais e o legado cultural construído e acumulado pela humanidade; e de tal forma preocupante que levou o filósofo Walter Benjamin, na década de 1930, a denunciar a instalação de uma nova espécie de barbárie dos tempos contemporâneos, advinda da miséria cultural provocada pelo desprezo às memórias e experiências individuais. ${ }^{5} \mathrm{O}$ fato de as histórias humanas (memórias, relatos, experiências, testemunhos) não encontrarem meios de circulação no todo social, submete as novas gerações ao abandono, à própria sorte, por se encontrarem privadas de referências "sensíveis", sem contato com experiências $^{6}$ que as ajudem a conhecer e a inserir-se no mundo.

$\mathrm{Na}$ maioria das comunidades de matriz africana no Brasil, as mulheres são lideranças que tomam a maior parte das decisões do dia-a-dia. Desnecessário dizer que as mulheres mais velhas são as que acumulam saber e conhecimento, por isso geralmente são requisitadas pelos membros da comunidade; elas constituem uma referência estrutural na existência e manutenção do espaço da tradição oral.

As dificuldades que a sociedade tem hoje de criar os meios de fazer circular o patrimônio cultural acumulado nas histórias de vida traz consequências irreparáveis à

\footnotetext{
${ }^{5}$ No ensaio "Experiência e pobreza", Walter Benjamin discute a problemática sociocultural implicada na crise da experiência no mundo contemporâneo. "Qual o valor de todo o nosso patrimônio cultural, se a experiência não mais o vincula a nós? A horrível mixórdia de estilos e concepções do mundo do século passado mostrou-nos com tanta clareza aonde esses valores culturais podem nos conduzir, quando a experiência nos é subtraída, hipócrita ou sorrateiramente, que é hoje em dia uma prova de honradez confessar nossa pobreza. Sim, é preferível confessar que essa pobreza de experiência não é mais privada, mas de toda a humanidade. Surge assim uma nova barbárie". (Benjamin, 1987, p. 114-19)

${ }^{6}$ Walter Benjamin fala sobre o rompimento dos vínculos com o passado e a atual situação de miséria em que vivemos, configurada pela "subtração da experiência".
} 
qualidade das relações humanas, em especial por dificultar as condições de articulação entre mundo subjetivo e objetivo dos sujeitos, uma das questões-chave que envolve a problemática da educação das novas gerações (reféns das dicotomias infernais).

Outrora, e não faz muito tempo, as "conversas" faziam parte da esfera do cotidiano. Quando os espaços públicos (a rua, a escola, a igreja, as feiras, as festas comunitárias etc.) constituíam extensões dos circuitos privados das relações interpessoais, os grupos sociais estavam mais expostos uns aos outros, criando redes de ensino-aprendizagem espontâneas. Nessas redes tecidas na esfera do cotidiano, a inclusão de conhecimentos e saberes capazes de "alimentar" o próprio grupo permitia que se aprendesse vivendo, ou seja, em situação real e cotidiana, trocando-se experiência e conhecimentos com os pares sociais.

Nessas relações sociais, junto com informações de ordem prática, transmitia-se todo um universo de conhecimento sensível indispensável à vida. $\mathrm{O}$ grupo, o meio e o indivíduo estavam permeados por um conjunto de referências comuns, acumuladas ao longo do tempo por gerações forjadas nos processos de convivência ordinária que, dentre outras coisas, favoreciam a construção de laços vinculantes e relações de afeto que reforçam a solidariedade do grupo em razão das dependências recíprocas que aquela condição de vida e sobrevivências determinavam.

\section{TRADIÇÃO ORAL E CAPOEIRA NA EDUCAÇÃO ESCOLAR}

O Centro de Estudos e Aplicação da Capoeira (CEACA) foi fundado em 1988, por Mestre Alcides de Lima e Mestre Dorival dos Santos, que elaboraram o Estatuto Social do grupo, com um projeto denominado "Expresse-se com consciência - faça capoeira"; a iniciativa foi pensada com o objetivo de trabalhar a capoeira principalmente em seus aspectos culturais, desenvolvendo no indivíduo suas aptidões para as artes em geral e também na educação formal.

A missão do CEACA é promover o desenvolvimento do cidadão como ser consciente e transformador da realidade onde está inserido, buscando a liberdade de expressão e autonomia do indivíduo de forma socialmente responsável, através da apropriação de elementos da sua cultura, a capoeira. Desde 1990, os mestres Dorival e Alcides têm levado a capoeira, para além dos muros da Escola, difundindo-a por vários 
locais no Brasil e no mundo. ${ }^{7}$ A filosofia do CEACA reside na busca da participação e a integração do indivíduo às artes em geral (música, dança, teatro, cantoria etc.), com desenvolvimento de suas habilidades e aptidões, tendo como fio condutor deste desenvolvimento, a cultura afro-brasileira e em específico a aplicação da capoeira. Grande instrumento de promoção da história e cultura brasileira, a capoeira se mantém muito próxima das danças folclóricas brasileiras (samba, coco, frevo e batuque, maculelê, entre outras), ligada diretamente à vida cultural, socioeconômica, e política do País.

A capoeira tem distinções de estilo que marcam, com bastante clareza, parte das modificações ocorridas em sua história. Sua origem (datada do século XVII, segundo alguns autores) é mais ou menos nebulosa. Supõe-se que tenha sido desenvolvida pelos africanos de etnia banto e seus descendentes vindos de Angola para o Brasil, mas parece contar com elementos indígenas e lusos. No século XX, entretanto, está suficientemente documentada para sabermos de mestre Pastinha e do estilo chamado Angola - tido como mais próximo, supostamente, da ritualística ancestral - em oposição ao estilo denominado Regional, de mestre Bimba, que, a partir de 1929, incorporou golpes e movimentos de outras lutas, enfatizando seu aspecto esportivo.

A prática da capoeira abrange elementos que colaboram para o desenvolvimento das capacidades físicas, passando pela expressão e consciência corporais, e das musicais, com as noções de ritmo, canto e execução de instrumentos (berimbau, pandeiro, atabaque, agogô, reco-reco). A capoeira é expressão corporal, depende do ritmo de seus instrumentos e de sua música que conta e canta a história de um povo que é milenar, assim como Grécia e Egito, com suas respectivas Mitologias. Como forma de expressão corporal, possui extensa variedade de movimentos, executados a partir da "ginga", que é considerada a espinha dorsal da capoeira, ou seja, é a sua base fundamental.

Capoeira é um jogo divertido e ao mesmo tempo, uma forma de luta bastante peculiar, pelo fato de a roda ser executada com acompanhamento musical, o que faz dela uma dança também. No interior da roda, há um sistema de alternâncias entre os parceiros. O jogo desenrola-se no centro de um círculo formado por outras pessoas - capoeiristas e espectadores - que, atentos, acompanham os movimentos dos dois jogadores, cantando e batendo palmas.

\footnotetext{
${ }^{7}$ LIMA, Alcides. (Org.) Capoeira \& Educação: coletânea de estudos e práticas. São Paulo: CEACA, 2012. Disponível para download em: https://capoeiraceaca.wordpress.com/referencias/.
} 
Principal instrumento musical da capoeira, o berimbau (primo distante do xitende) comanda a roda, determinando o estilo de jogo, quem joga e quem não joga. Dizse até que o berimbau fala. As músicas - em sua maioria cantadas em português - contam as histórias do povo e aquilo que acontece na própria roda, que é concebida como uma representação da realidade em que vivemos.

Os mestres e aprendizes da tradição oral valorizam a arte da capoeira, que pode ser trabalhada de acordo com múltiplos enfoques: na questão social e na afirmação da identidade étnica e consequentemente na valorização da autoestima dos indivíduos praticantes. Tais práticas fortalecem a continuação da ancestralidade ao formar cidadãos capazes de multiplicá-las, fator hoje em dia muito importante para a preservação da cultura afro-brasileira. Em defesa da memória e cultura de seu povo, diz o Mestre:

A ancestralidade não é desvinculada do corpo; aliás, este é um elemento muito importante para expressá-la. Podemos, então, considerar que o corpo também é o lugar dela, sendo o principal instrumento de resistência das práticas de tradições orais. Consideramos a possibilidade de levar na memória e em nosso próprio corpo determinado inventário e de tornar a prática como presença, como certa matriz a continuar a tradição. (Lima, 2017, p. 155)

Por intermédio da cultura, Mestre Alcides de Lima realiza dois movimentos em busca dessas ancestralidades: participa de pesquisas para colher relatos e material sobre o Jongo em diversos estados brasileiros e, desde 2000, ensina capoeira e cultura afrobrasileira na EMEF Des. Amorim Lima (zona oeste, Butantã-SP), com base em projeto pedagógico desenvolvido ao longo de várias décadas, trabalhando com os valores da "ancestralidade" dos povos tradicionais de matriz africana. ${ }^{8}$

A proposta do CEACA foi acolhida pela escola que se inspirou em uma metodologia criada em escolas portuguesas, a Escola da Ponte, ${ }^{9}$ também conhecida como

\footnotetext{
${ }^{8}$ Entre os séculos XVI e XIX, o Brasil recebeu aproximadamente cinco milhões de africanos e africanas, na condição de homens e mulheres escravizados: trouxeram para o país, além de sua força de trabalho, tecnologias agrícolas e de mineração, culturas, saberes, tradições e valores civilizatórios. Esses povos são originários de diversas regiões do continente africano que compreende os países de Angola, Congo, Moçambique, Benin, Togo, Gana, Guiné, Nigéria, Senegal, dentre outros. A despeito de toda a violência do sistema escravista e do racismo pós-abolição, eles mantiveram vivas suas tradições e práticas culturais. Três grandes matrizes culturais - Yorùbá, Bantu e Ewé Fon - conseguiram preservar muito de suas cosmovisões e saberes tornando-os marcas indeléveis na história e no modo de ser e viver brasileiros. Essas matrizes culturais se reelaboraram dando origem a territórios tradicionais, com diversas denominações, de norte a sul do país. In: COSTA, Carmen C. Lustosa da. Comunidades tradicionais de matriz africana. 09/04/2014. Disponível em: http://www.seppir.gov.br/comunidades-tradicionais/comunidadestradicionais-de-matriz-africana.

${ }^{9}$ A Escola da Ponte é uma escola pública que, desde 1976, procura um sentido próprio na qualidade de educação que promove. Enquadrada num paradigma de racionalidade emancipatório que se afasta do modelo tradicional, está organizada segundo uma lógica de projeto e de equipe, estruturando-se a partir das
} 
a "Escola sem Paredes", um projeto pedagógico diferenciado e multifocal no que concerne à forma de educar as crianças. Entre as disciplinas do currículo, os alunos têm um tempo reservado para o aprendizado da cultura popular brasileira, através de manifestações da tradição oral. A metodologia integra atividades em espaços sem paredes, sem regência de aulas por disciplina específica e com a participação ativa dos alunos mais avançados em auxílio aos iniciantes.

As oficinas de capoeira têm como objetivo a integração e participação dos indivíduos às artes em geral, utilizando a capoeira como método de ensino e aprendizagem. Um ponto diferencial do projeto está na visão artística e social de sua aplicação, como forma de libertação das habilidades e aptidões individuais. Toda e qualquer atividade cultural visará o engrandecimento do indivíduo através da capoeira, porque, dentro desta visão, esta atividade proporcionará desenvolvimento do raciocínio lógico com muito equilíbrio emocional.

$\mathrm{Na}$ capoeira, existe um compartilhamento do seu conhecimento na sua maneira de ser, de saberes e fazeres, é nela também que invocamos uma situação de pertencimento a um grupo ou comunidade, situação tão rara na atualidade urbana em que vivemos. Nesse sentido, a roda também é formadora, o aprendizado vai do micro para o macro, como da família para sociedade, ou da roda para as relações na sociedade, num ressoar em ondas que não pode ser invertido:

A capoeira sempre fez parte, de maneira profunda e orgânica, de nossa cultura popular, aliás, sempre foi apropriada na dinâmica do imaginário coletivo em nossa nação. No decorrer das últimas décadas, vem sendo fortemente assimilada pelas instituições, escolas, universidades, espetáculos teatrais e mídia, documentários, passando por uma apropriação institucional que se revela importante para a dinâmica dos nossos dias, por vários motivos. Existem questões importantes no ato lúdico; é no brincar que simbolizamos a vida e nos formamos, tanto na infầncia, quanto no resgate desta brincadeira na vida adulta. $\mathrm{O}$ lúdico possui - ao contrário do que a sociedade tradicional apregoa com visão negativa sobre o ócio, almejando sempre produtividade nas ações - mecanismos efetivos para desenvolvermos as emoções e convivermos com o outro. (Lima, 2012, p. 23, grifo nosso).

No que se refere às manifestações culturais afro-brasileiras, Mestre Alcides de Lima argumenta que "é importante ampliar os conhecimentos envolvendo outras

interações entre os seus membros. Liderados por José Pacheco, na escola da Ponte todos trabalham com todos. Nenhum aluno é aluno de um professor só, nem um professor é professor só de alguns alunos. Assente em valores como a solidariedade, autonomia e responsabilidade, é um marco pedagógico de diferenciação, com mais de 40 anos de história, estudado e admirado um pouco por todo o mundo. Fonte: http://www.escoladaponte.pt/. 
possibilidades de abordagem, explorando a diversidade cultural", o que significa poder trabalhar, além da capoeira, com diferentes manifestações culturais afro-brasileiras e indígenas, empregando diferentes metodologias. Todas as oficinas de trabalho são planejadas e desenvolvidas no espaço da escola (com grupos de 20 a 30 crianças do ensino fundamental), sob a coordenação de um mestre da tradição oral, em palestras específicas sobre os temas, com a realização das seguintes propostas de atividades:

- Oficinas de Coco: visa à integração e participação dos indivíduos no reconhecimento e na prática da manifestação cultural do coco por meio de aulas praticas com explicações de sua origem, historia, forma de dançar, tocar instrumentos e a métrica dos versos, são destinadas às crianças de $1^{\mathrm{a}}$ à $8^{\mathrm{a}}$ série uma vez a cada quinze dias com a presença do mestre Durval do Coco.

- Oficinas de Samba de Roda: visa à integração e participação dos indivíduos no reconhecimento e na prática da manifestação cultural do samba de roda as suas origens, a sua importância histórica no processo de formação cultural brasileira como dançar, cantar e tocar os instrumentos, destinadas às crianças de $1^{\mathrm{a}}$ à $8^{\mathrm{a}}$ série uma vez a cada quinze dias; explicar sua história, como organizar uma roda, quem dança, indumentária, em que local do Brasil é dançado de forma mais original (Recôncavo Baiano)

- Oficinas de Puxada de Rede e Pesca do Xaréu: visa à participação dos indivíduos no reconhecimento e na prática da manifestação cultural da puxada de rede e pesca do xaréu; ${ }^{10}$ suas origens, a sua importância histórica no processo de formação cultural brasileira, como dançar, cantar e tocar os instrumentos, destinadas às crianças de $1^{\mathrm{a}}$ à $8^{\mathrm{a}}$ série uma vez a cada quinze dias.

- Oficinas de Maculelê: visa à integração e participação dos indivíduos no reconhecimento e na prática da manifestação cultural do maculelê, ${ }^{11}$ e suas origens, a sua importância histórica no processo de formação cultural brasileira como dançar, cantar e tocar os instrumentos, destinadas às crianças de $1^{\mathrm{a}}$ à $8^{\mathrm{a}}$ série uma vez a cada quinze dias.

- Oficinas de Música: busca estimular o aprendiz a desenvolver o gosto pela musicalidade que é parte indissociável da cultura popular brasileira, através de aulas de percussão e vocal, onde são ensinados os toques básicos e cantigas,

\footnotetext{
${ }^{10}$ A Puxada de Rede surgiu após o período da escravidão, quando os negros não se encaixaram no mercado de trabalho e procuram seu sustento no mar; uma parte destes negros se deslocou para as entranhas dos mangues, na região de Santo Amaro-BA. A puxada da rede do xaréu (tipo de peixe) é uma das heranças mais interessantes dos tempos da escravidão, sobretudo pelo aspecto folclórico, que transformou um labor fatigante em uma das mais agradáveis atrações das praias baianas. Tendo em vista o desenvolvimento tecnológico da pesca e outros fatores relacionados com o meio ambiente, essa atividade artesanal encontrase em decadência desde a década de 1970, sendo exercida, esporadicamente, somente por algumas das pequenas colônias de pescadores existentes ao longo da orla marítima da Bahia; e, além disso, sem o encanto e a magia dos tempos passados.

${ }^{11} \mathrm{O}$ Maculelê é uma manifestação cultural da Bahia, berço também da capoeira. É uma expressão teatral que conta, através da dança e dos cânticos, a lenda de um jovem guerreiro, que sozinho conseguiu defender sua tribo de outra tribo rival usando apenas dois pedaços de pau, tornando-se o herói da tribo. É um tipo de dança folclórica brasileira de origem afro-brasileira e indígena. A origem do Maculelê tem diversas lendas ao seu redor. Tais lendas, naturalmente, vieram da tradição oral característica às culturas afro-brasileira e indígena da época do Brasil Colônia e inevitavelmente sofreram alterações ao longo do tempo.
}

Revista da ABPN • v. 11, Ed. Especial - Caderno Temático: Cultura popular em cena: artes afro diaspóricas • julho de 2019, p.130-154 
utilizando-se o berimbau, pandeiro, atabaque e outros instrumentos usados nas manifestações culturais praticadas no projeto, destinadas às crianças de $1^{\mathrm{a}}$ à $8^{\mathrm{a}}$ série, uma vez a cada quinze dias.

- Congados: aulas com mestres dos Congados, de Folias de Reis, Maracatus, Tambor de crioula, Bumba meu Boi ou Boi Bumbá, Ciranda; audição das histórias dos Mestres, pela Oralidade;

- Frevo: descrição de sua história, sua ligação com Pernambuco, época do surgimento, sua função nas abre alas das festas, sabemos que ele é filho primogênito da capoeira;

- Literatura oral: contação de história, mitos africanos e indígenas, musicalidade, provérbios, literatura de cordel, repentes, aboios;

- Toré: dança de vários grupos indígenas; ritual que envolve uma dança circular (em fila ou pares) acompanhada por cantos, ao som de maracás, zabumbas, gaitas e apitos, de grande importância para os indígenas. ${ }^{12}$

$\mathrm{Na}$ educação popular, é constante o convívio entre indivíduos de diferentes idades, diversificando as interações. Os mais velhos contam aos mais novos as histórias do passado, ensinam os cantos, as danças, transmitindo oralmente estes saberes, cumprindo o papel do griô tradicional. O espaço educativo da capoeira - seja aula, treino ou roda - promove apropriadamente encontros das diversas gerações interessadas em sua prática. Associada ao espaço da educação formal nas escolas, a aplicação constante de exercícios técnicos de luta, jogo, ritmo, dança, ginga, teatro e brincadeiras preenchem lacunas que incluem a multidisciplinaridade.

Durante as aulas de capoeira, que exploram uma diversidade de músicas, danças e brincadeiras, os exercícios de alongamento, aquecimento e o próprio desenvolvimento corporal se tornam mais agradáveis, dinâmicos, lúdicos e integrados. Tal metodologia demonstra que as danças e brincadeiras de outras manifestações culturais se interligam com a capoeira, por isso, estes movimentos podem ser integrados aos movimentos típicos da capoeira, enriquecendo a expressão corporal. A ginga é expressão pessoal, construída de forma singular pelo(a)s capoeiristas. É possível deixar a ginga mais solta, mais leve e criativa ou mesmo atacar e se defender com movimentos presentes em passos de samba, coco, frevo, maculelê e de tantas outras manifestações culturais.

As rodas de conversa e aplicação da capoeira são coordenadas por mestre Alcides de Lima e o ponto de cultura atende cerca de 300 crianças de $1^{\text {a }}$ a $4^{\mathrm{a}}$ série. De acordo com a versão do mestre, as aulas sobre a cultura popular do ponto de cultura fogem

\footnotetext{
12 “[...] Como um caleidoscópio o Toré reordena e elabora saberes múltiplos sobre a natureza, o tempo e o imaginário social, celebrando a vida, a criação permanente e afirmando a possibilidade futura de uma comunidade imaginada e benfazeja entre todos os que dela participam". (OLIVEIRA, 2005, p.10).
} 
dos padrões do ensino formal das escolas brasileiras. A oralidade tem como base significativa a "reiteração" - enunciação de palavras e ideias já evocadas antes - e que as crianças aprendem através da repetição de histórias, cantos, contos, poesias, entre outras manifestações artísticas.

Figura 1 - Roda de capoeira infantil, batizado do Amorim Lima, 15.12.2013.

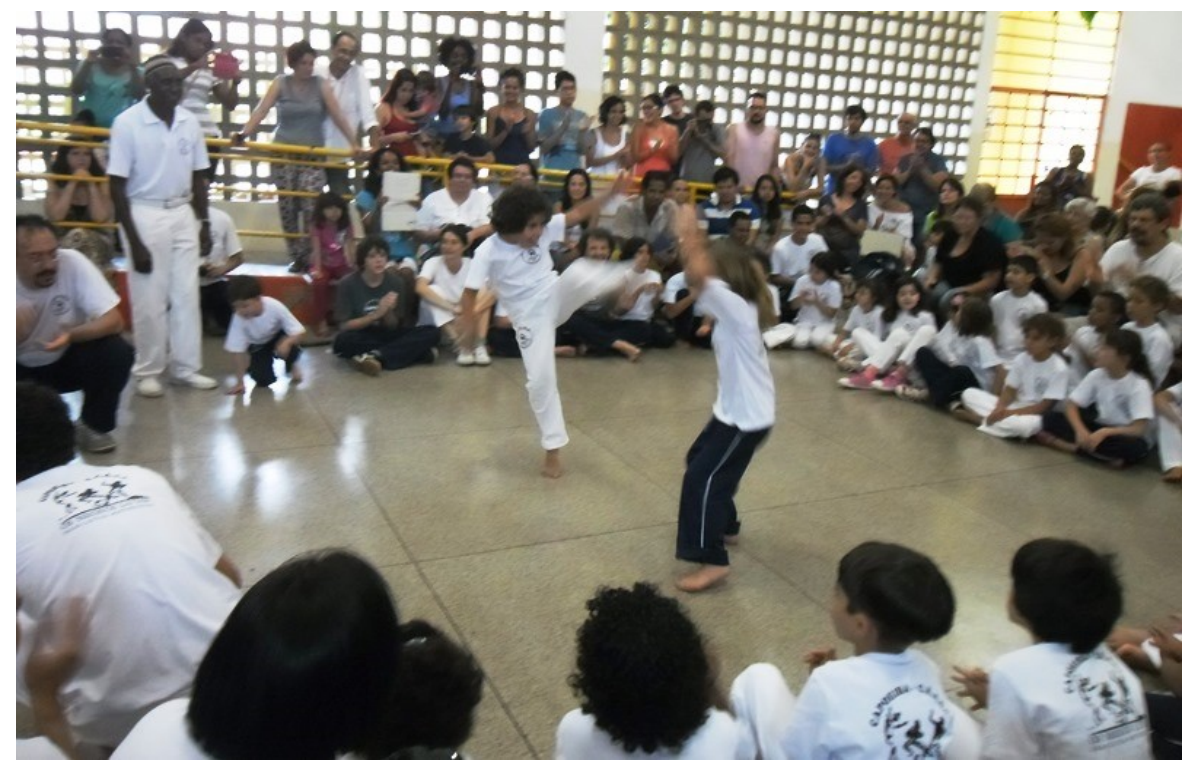

Fonte: https://capoeiraceaca.wordpress.com/publicacoes/amorim-lima/.

O ensino da tradição oral complementa a educação formal. As rodas de capoeira do CEACA são espaços de vivência e trocas de saberes, nos quais especialmente crianças e adolescentes carentes têm oportunidade de exercitar o canto, a voz, o corpo e o protagonismo social em suas relações com o patrimônio cultural disponibilizado nas danças, cantos e rodas que as compõem.

A roda se configura em todas as culturas como uma união espontânea, onde não importa a técnica e sim o sentimento de união de grupo; a roda da capoeira, dentre outras rodas importantes no nosso brincar (ciranda, coco de roda, samba de roda, maculelê, o toré, a peteca...) são práticas tradicionais, que possuem um papel unificador social. E neste vínculo, o sagrado também está presente, o círculo nasce quando os participantes entram em contato com a parte de seu ser que está intimamente conectada com algo transcendental. Portanto, o "Círculo" ou "Esfera" é uma representação do universo micro e macro; a disputa por espaço no meio da roda, no jogo ou na luta também faz parte das 
relações a serem mediadas na vida, e da maneira como nos comportamos e agimos neste espaço.

Rodas de capoeira e de conversa são dispositivos culturais vivos onde vários enunciados e significados são apresentados e descobertos pelos sujeitos, sempre que são acionados coletivamente, desde a roupa, a postura, a ordem de entrada e saída, passando pela fala, pelo canto e instrumentos musicais (berimbau, agogô, atabaque, pandeiro, viola). São ambientes onde circula um universo cultural rico de significados, são espaços de aprendizagem que se constituem como "lugares" de busca, de apropriação e negociação diante de manifestações culturais. Os participantes das rodas têm a oportunidade de demonstrar na prática a versatilidade e a dinâmica dos corpos em movimento e agregam ao conceito da capoeira a possibilidade de realização pessoal por meio de mediações culturais.

A roda de capoeira é um círculo com uma bateria musical em que a capoeira é jogada, tocada e cantada: serve tanto para o jogo, divertimento e espetáculo, quanto para aplicar o que se aprende durante o treinamento. Uma roda de capoeira é mais do que um lugar ou ambiente; é um dispositivo cultural no qual parceiros/amigos se encontram para descobrir no jogo, na luta, na dança e nas ações desenvolvidas a partir dela, motivações e significações como possibilidades de se posicionar de maneira crítica e produtiva diante do mundo; são diversas e variadas as modalidades de leitura que perpassam as práticas e execuções pedagógicas conduzidas por um mestre de capoeira a seus alunos (orais, visuais, gestuais, presenciais, cognitivas, afetivas etc.).

\section{PEDAGOGIA GRIÔ E REINVENCÃO DA RODA DA VIDA}

Historicamente, em muitas situações, a escola desempenhou o perverso papel de ignorar e apagar a lembrança em comunidades, sobretudo rurais, que antes de sua chegada eram muito ricas de saberes. Isso aconteceu e ainda acontece em diversas unidades escolares brasileiras porque a escola encontra-se totalmente estruturada a partir da cultura escrita e de um conhecimento que se pretende universal. Neste contexto, os mestres de tradição oral de uma comunidade, os quais até então eram as suas principais referências de saber e sabedoria, costumam ser taxados de analfabetos e desdenhados pela escola.

A percepção da população em relação ao modelo da escola tradicional é que o espaço pedagógico é desinteressante, as escolas não estão preparadas para trabalhar com 
a diversidade de saberes ou diversidade epistemológica. A promulgação da Lei $\mathrm{n}$. 10.639/2003 - que altera a Lei de Diretrizes e Bases da Educação Nacional (LDB), Lei n. 9.396/1996, e inclui no currículo oficial dos estabelecimentos de ensino básico das redes pública e privada do país a obrigatoriedade do estudo da temática "História e Cultura Afro-Brasileira e Africana" - é essencial para eliminar a desigualdade presente no sistema educacional brasileiro. Ela cumpre princípios estabelecidos pela Constituição de 1988 e pela LDB que asseguram o direito à igualdade de condições de vida e de cidadania, assim como garantem igual direito às histórias e culturas que compõem a nação brasileira, além do direito de acesso às diferentes fontes da cultura nacional a todos brasileiros.

Em 2008, a lei supracitada foi alterada pela Lei n. 11.645/2008, que incluiu a obrigatoriedade do ensino da história e da cultura afro-brasileira e também indígena. Com essas duas alterações na LDB, a instituição escolar foi concebida legalmente como um espaço central na discussão e superação do racismo e de outras formas de discriminação. A valorização da identidade negra e também indígena na escola conformam ações iniciais para uma educação antirracista que deve promover o fortalecimento da autoestima e afirmação da diversidade cultural, para a construção de relações étnico-raciais positivas dentro e fora da escola. ${ }^{13}$

É neste contexto que foi concebida a "pedagogia griô". Trata-se de uma prática pedagógica que convida a descobrir a imensa liberdade que é poder ser quem se é dentro da escola; ou seja, em vez de impor um saber como correto, opta por construir - sem limitações a priori - vias de saber que digam respeito diretamente às pessoas que, de fato, estão ali vivenciando o processo educativo, com as suas tradições culturais, os seus saberes ancestrais; enfim, junto com as suas famílias, e ao mesmo tempo com os seus interesses de conhecer outros mundos e outras realidades, de desenvolver o saber crítico sem com isso cortar suas raízes, sua identidade.

Em outros termos, para retomar uma expressão do Paulo Freire, significa abrirse para "ser mais" e não diminuir-se e submeter-se a um conhecimento externo, que provavelmente serve a outros grupos sociais, econômicos e políticos.

O que é invisível para uns é a escola da vida para outros. Nas capoeiras, candomblés, sambas-de-roda, torés, cirandas, nas escolas de samba, nas

${ }^{13}$ COSTA, A. C. F. da. Educação, turismo e ação griô: impactos da modernidade na comunidade quilombola do Remanso (Lençóis-BA). Dissertação (Mestrado) - Universidade de São Paulo, 2015. 
caminhadas de reis, nas mãos de rendeiras e parteiras, no encontro com griôs... Vemo-nos em rodas, rituais, coros e cantos ancestrais chamando para responder... Cores e movimentos fluidos, seguros, quentes e leves como a água, a terra, o fogo e o ar. As idades e os gêneros juntos em caminhadas e conversas com todas as linguagens artísticas e afetivas da corporeidade humana. Contadores de histórias, heróis e mitos que dão sentido aos mistérios de cada idade da vida. O grupo como colo, ninho, família, comunidade e o princípio da partilha como economia. A palavra como poder divino e o universo como expressão, fala, forma, música e dança - da vida em evolução. (Pacheco, 2006, p. 83)

O saber do Mestre Griô é um nome-síntese de trajetórias agregadoras, múltiplas, híbridas, mestiças e inovadoras do povo brasileiro. O saber do Mestre Griô não representa uma unidade cultural, ao contrário, expressa a diversidade de um povo que aprendeu a construir sua identidade com o Outro. O saber do Mestre Griô é um nome que age como uma metáfora de que o "eu" é sempre o resultado do diálogo com o "outro", ou melhor, o eu é também o outro. (Lazaneo et al., 2016, p. 249)

O termo "griô" simboliza uma forte expressão tanto da valorização dos saberes orais oriundos dos recônditos rurais e das cidades do Brasil, quanto da valorização do encontro entre a brasilidade e o mundo diverso que a compôs. Assim, o saber do griô está calcado na tradição oral, definida como um saber que é transmitido de geração em geração, e que reinaugura a cada novo nascimento a reprodução de si própria. A tradição oral pode ser entendida como um saber que habita o corpo e que se expressa pelo contar histórias, pelo encantamento sonoro e por objetos que carregam uma longa historicidade. (Lazaneo et al., 2016, p. 250)

Segundo relata Alcides de Lima, griôs e mestres da tradição oral "são todos aqueles e aquelas que detêm um saber que vem sendo transmitido por várias gerações, secular ou milenar através da oralidade, e se reconhece e é reconhecido/a por sua comunidade". Ou seja, a construção se materializa por meio das histórias do seu povo no interior da rede de histórias das comunidades. Nesse universo, não se pode enfatizar uma etnia ou uma cultura específica, pois as suas singularidades somente adquiriram importância na diversidade do diálogo com outras culturas.

As sociedades africanas eram vistas como sociedades que não podiam ter história, por falta de documentos e fontes; mas, a sua riqueza "está fundamentalmente baseada no diálogo entre indivíduos e na comunicação entre comunidades ou grupos étnicos" (Pacheco, 2006, p. 41) e "os Griôs são os agentes ativos e naturais" das conversações que acontecem ao longo das gerações, neste movimento de afirmação 
contínua da ancestralidade. Ou seja, a construção se faz por meio das histórias do seu povo no interior da rede de histórias dos povos. De um lado, a sabedoria do Mestre Griô reconhece que sua existência só foi possível graças aos antepassados que a criaram, por meio de um movimento dinâmico de culturas em frequente formação. Por outro, tal sabedoria expressa total entrega ao mundo de sua comunidade. Sua cultura é mais que sua casa, é sua habitação. Uma habitação reconstruída pelas narrativas dos Mestres Griôs, feita de lendas, mitos, origens e cosmologias locais, mas também de troca intensa, aprendizado e diálogo com outras histórias.

O saber do Mestre Griô é uma forma de definirmos tudo que nos é familiar, e é por meio das histórias dos mestres que os objetos da cultura adquirem vibração. Tambores, redes, tapetes, vasilhas, muzuás, artesanatos etc., adquirem vibração e vida, graças às histórias (re)contadas pelos Mestres Griôs. Esta cultura que se reproduz sem capitalizar, ou seja, sem intencionar a dominação do tempo, tem seu grande fundamento na intenção de compartilhar vivências. Atua como um saber ainda não sabido pela escola, que reinaugura a arte de contar histórias como uma arte de moldar percursos e trilhas. (Lazaneo et al., 2016, p. 251-53) De acordo com as palavras de Tierno Bokar Salif, respeitado mestre da ordem muçulmana de Tijaniyya e tradicionalista em assuntos africanos:

A escrita é uma coisa, e o saber, outra. A escrita é a fotografia do saber, mas não o saber em si. O saber é uma luz que existe no homem. A herança de tudo aquilo que nossos ancestrais vieram a conhecer e que se encontra latente em tudo o que nos transmitiram, assim como o baobá já existe em potencial em sua semente. (Bokar apud Bá, 2010, p. 167).

O saber do Mestre Griô não é periférico, mas é o centro da espiral da cultura... O Mestre Griô revela o que há de mais vivo e ancestral no mundo, mas também socializa e atualiza para todos nós as tradições de seu povo. Não é por acaso, que na África os Mestres Griôs eram poupados da participação nas guerras, pois se morressem, não significaria a morte de uma pessoa, mas do fundamento de uma cultura. Em algumas regiões da África Ocidental, os Mestres Griôs ao morrerem eram "enterrados" no interior das árvores (Baobá, por exemplo), para que suas narrativas continuassem a fertilizar a cultura, assim como as folhas de uma árvore fazem com o seu entorno. 
O saber do Mestre Griô não é simplesmente uma voz elaborando uma performance, ${ }^{14}$ mas um saber corporal, visual, sonoro e verbal que espirala a cultura. É a metáfora da abertura da brasilidade ao mundo e o simbólico da necessidade de inserção das culturas orais na educação. O saber do Griô é definido pela historicidade das trilhas e caminhos, que agem como transveredas culturais e é levado pelo desejo de compartilhar suas narrativas, promovendo o encontro com outras histórias e compondo um verdadeiro conhecimento partilhado. O saber do Mestre Griô é rede, laços que sobrepõem nações, culturas, corporeidades e que tem muito o que colaborar na educação e na cidadania brasileiras. (Lazaneo et al., 2016, p. 254-55).

Este saber oral tem como primordial fundamento a intenção de compartilhar vivências, que podem estar inscritas em diferentes contextos, nos rituais religiosos, nas festas, danças, musicalidade, rodas de capoeira, de samba, rodas de conversa etc. ${ }^{15} \mathrm{O}$ sagrado está presente em toda a parte. Da preparação das comidas ao momento das celebrações, festejar juntos é reverenciar os antepassados e pertencer, portanto, a uma unidade comunitária com interesses comuns, um forte componente do sistema simbólico eficiente das culturas de tradição oral.

No universo da tradição oral, as referências são as práticas construídas em territórios simbólicos diferenciados tais como: terreiros de candomblé, capoeiras, torés, sambas de roda, reisados, folias de Reis, cantos do trabalho, festas populares e literários dos cordelistas e repentistas; na ciência das parteiras, na habilidade das rendeiras, antevisão dos pais e mães de santo, brincadeira dos bonequeiros; na medicina dos curadores, erveiras, benzedeiras e xamãs; no jongo, congo, cacuriá, carimbó, ciranda, maracatu, coco, cavalo marinho, siriri; nas artes do circo, teatro de rua, mamulengo, catira, pastoril; na biblioteca viva dos contadores de histórias e em todas as artes integradas aos mitos e às ciências da cultura oral. ${ }^{16}$

Figura 2 - Cortejo com mestres da tradição oral, 2016.

\footnotetext{
14 "Performance é reconhecimento. A performance realiza, concretiza, faz passar algo que eu reconheço, da virtualidade à atualidade". (Zumthor, 2000, p. 36)

${ }^{15}$ Leia a entrevista de Sérgio Bairon, professor da USP que fala sobre a Lei Griô. 2012. Disponível em: https://www.youtube.com/watch?v=IuYfzkdFRqQ\&feature=plcp. Acesso em: 08.04.2018.

${ }^{16}$ PACHECO, L. A pedagogia griô: educação, tradição oral e política da diversidade. In: Revista Diversitas, São Paulo, ano 2, n. 3, set.2014-mar.2015.
} 


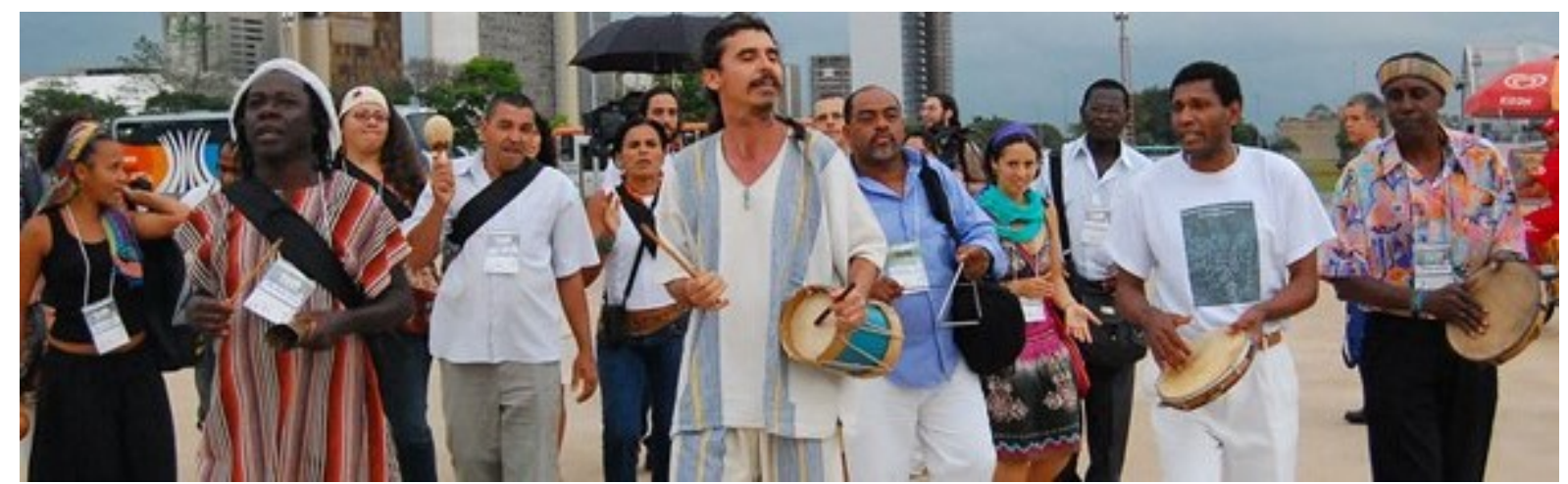

Fonte: http://www.acaogriobahia.org.br/.

Tal como o "sangue que circula", são reconhecidos como Griôs, Aprendizes de griô ou Mestres aqueles que fazem com que as tradições circulem entre as novas gerações, preservando a identidade cultural de cada povo. Essas pessoas guardam os saberes e tradições de cada comunidade: se os mestres ganham visibilidade, começam a ser reconhecidos em seus locais de origem.

Para os aprendizes de griô, os mestres da tradição oral são "guardiões, fonte em que buscam a renovação das forças e a alegria para caminhar. E os saberes da tradição oral são o ativo estratégico para continuarmos a riqueza da diversidade cultural brasileira”. A capoeira é trabalhada como "uma possibilidade humana de educação". Por meio dela é possível agregar valores às crianças. "Porque dentro da capoeira tem toda uma questão de resgate de valores, como o respeito, o reconhecimento, entender porque as pessoas não são iguais, que cada um tem a sua dificuldade, que um complementa o outro". 17

\section{CONSIDERAÇÕES FINAIS}

As várias modalidades de ensino tradicional, centradas na transmissão de informações pelo professor, estão cada vez mais em descrédito, superadas por novos modos de ensinar e aprender, baseados, sobretudo, em premissas que tomam o aprendiz como sujeito e não como simples objeto dos processos de conhecimento. Em face dos quadros histórico-culturais da contemporaneidade, o transmissivismo pedagógico vai perdendo o sentido e a centralidade que teve no passado, substituído por modalidades que

\footnotetext{
${ }^{17}$ Reportagem publicada no Brasil de Fato. Fonte: http://www.brasildefato.com.br/node/246.
} 
têm os processos de construção de conhecimento como categoria organizadora da nova ordem pedagógica. (Santos, 2012, p. 97-98)

A prática das rodas de capoeira integra uma espécie de fazer antropotécnico cujo saber ancestral prepara os participantes para um estado de prontidão, para as novas leituras do mundo, a recepção de informações legíveis no seu entorno, alimentando e ampliando o repertório para potencialmente criar novas autorias. A conversa trocada na roda, não escrita, tem o corpo como porta-voz, o que amplia a capacidade de os participantes lerem melhor seus pares e a própria interação no jogo. Essas leituras "ágrafas" dão condições de se desenvolver cognitivamente, e o mais importante: formam o indivíduo, fazem-no sentir-se parte integrante de um grupo. Nesse sentido, a roda de capoeira é formadora, o aprendizado vai do "micro" ao "macro", da família para a sociedade ou da roda para as relações sociais, num ressoar em ondas que não pode ser invertido. A hierarquia, conhecimento e sabedoria dos mais velhos são muito importantes para essa cultura e extrapolam o âmbito da memória.

As relações sociais em culturas de tradição oral são mais empáticas que contratuais. As relações são vinculantes porque são relações de afeto, são guiadas por interesses comuns e gostos compartilhados, a exemplo das rodas de capoeira, rodas de conversa, rodas de samba e as giras dos terreiros de Candomblé; estes lugares de memória são o suporte territorial de comunidades litúrgicas no qual se afirma a cultura do antigo escravo africano diante da produção simbólica hegemônica e apresenta-se como o lugar de materialização, construção e reconstrução do modo cultural negro-brasileiro ou afrobrasileiro.

\section{REFERENCIAS}

BÂ, A. H. A tradição viva. In: KI-ZERBO, J. (Coord.) História Geral da África I: metodologia e pré-história da África. 2a ed. rev. Brasília: UNESCO, 2010, p. 167-212.

BENJAMIN, W. Magia e técnica, arte e política. São Paulo: Brasiliense, 1987.

BOSI, E. Memória e sociedade: lembrança dos velhos. $3^{\text {a }}$ ed. São Paulo: Companhia das Letras, 1994.

BURKE, P. Vico. Trad. Roberto Leal Ferreira. São Paulo: Ed. Unesp, 1997.

CEACA. Centro de Estudos e Aplicação da Capoeira. Referências. Disponível em: https://capoeiraceaca.wordpress.com/referencias/. Acesso em: 06 ago 2018. 
CÂMARA CASCUDO, L. da. Tradição, ciência do povo. Pesquisas na cultura popular do Brasil. São Paulo, Editora Perspectiva, 1971.

CORACINI, M. J. Desconstruindo o discurso de divulgação: as questões do significado e da autoria. In:

ARROJO. R. (Org.) O signo desconstruído. Campinas: Pontes, 1992.

COSTA, A. C. F. da. Dos griots aos griôs: a importância da oralidade para as tradições de matrizes africanas e indígenas no Brasil. In: Revista Diversitas, São Paulo, Ano 2, n. 3, p. 385-396, set. 2014/mar. 2015.

COSTA, C. C. L. da. Comunidades tradicionais de matriz africana. 09/04/2014. Disponível em: http://www.seppir.gov.br/comunidades-tradicionais/comunidades-tradicionais-de-matriz-

africana.

GEERTZ, C. O saber local: novos ensaios em antropologia interpretativa. $14^{\mathrm{a}}$ ed. Petrópolis: Vozes, 2014, p. 77-97.

HALBWACHS, M. A memória coletiva. São Paulo: Centauro, 2006.

LAZANEO, C. Produção partilhada do conhecimento: uma experiência com as comunidades indígenas Xavante e Karajá. 2012. Dissertação (Mestrado em Teoria e Pesquisa em Comunicação), Escola de Comunicações e Artes, USP, São Paulo, 2012.

LAZANEO, C.; BATTISTELLA, R. N.; BAIRON, S. Fundamentos da produção partilhada do conhecimento e o saber do Mestre Griô. In: Revista Diversitas, São Paulo, n. 3, p. 246-65, abr. 2016.

LIMA, A. de. (Tserewaptu). Eu e minha ancestralidade: o encontro de saberes. In: Revista Observatório Itaú Cultural, n. 22, maio/nov. São Paulo: Itaú Cultural, 2017, p. 153-163.

LIMA, A. de. Capoeira \& Educação: coletânea de estudos e práticas. São Paulo: CEACA, 2013.

MAFESSOLI, M. O conhecimento comum: introdução à sociologia compreensiva. Porto Alegre: Sulina, 2010.

OLIVEIRA, J. P. de. Toré: regime encantado do indio do Nordeste. Recife: Fundaj, Ed. Massangana, 2005.

PACHECO, L. A pedagogia griô: educação, tradição oral e política da diversidade. In: Revista Diversitas, São Paulo, ano 2, n. 3, set.2014-mar.2015.

PACHECO, L. Pedagogia griô: a reinvenção da roda da vida. Lençóis-BA: Grãos de Luz e Griô, 2006.

RODRIGUES, A. D. Comunicação e cultura: a experiência cultural na era da informação. Lisboa: Editorial Presença, 1994.

SANTOS, Edison Luís dos. Infoeducação e cultura quilombola: uma perspectiva de diálogo entre sujeitos e saberes. In: Revista da Associação Brasileira de Pesquisadores/as Negros/as (ABPN), [S.1.], v. 3, n. 6, p. 95-111, fev. 2012. Disponível em: http://abpnrevista.org.br/revista/index.php/revistaabpn1/article/view/354.

Revista da ABPN • v. 11, Ed. Especial - Caderno Temático: Cultura popular em cena: artes afro diaspóricas $\bullet$ julho de 2019, p.130-154 
ZUMTHOR, P. Performance, recepção, leitura. São Paulo: Educ, 2000.

Recebido em 30/04/2019 Aprovado em: 30/06/2019 